\title{
Higher fear of predators does not decrease outdoor range use in free-range Rowan Ranger broiler chickens
}

Caroline Lindholm, Louise Karlsson, Alexandra J ohansson and J ordi Altimiras

The self-archived postprint version of this journal article is available at Linköping University Institutional Repository (DiVA):

http:/ / urn.kb.se/ resolve?urn=urn:nbn:se:liu:diva- 140981

N.B.: When citing this work, cite the original publication.

This is an electronic version of an article published in:

Lindholm, C., Karlsson, L., J ohansson, A., Altimiras, J ., (2016), Higher fear of predators does not decrease outdoor range use in free-range Rowan Ranger broiler chickens, Acta agriculturae

Scandinavica. Section A, Animal science, 66(4), 231-238.

https:// doi.org/ 10.1080/ 09064702.2017.1337214

Original publication available at:

https:/ / doi.org/ 10.1080/09064702.2017.1337214

Copyright: Taylor \& Francis (STM, Behavioural Science and Public Health Titles)

http:// www.tandf.co.uk/journals/default.asp 
Higher fear of predators does not decrease outdoor range use in free-range Rowan

\section{Ranger broiler chickens}

Caroline Lindholm*, Louise Karlsson, Alexandra Johansson and Jordi Altimiras

AVIAN Behavioural Genomics and Physiology group, IFM Biology, Linköping University, 58183 Linköping, Sweden

*Corresponding author: caroline.lindholm@liu.se 


\begin{abstract}
Organic chicken production is currently experiencing a boom in Sweden, but has only recently gained access to a commercial slow-growing broiler strain, the Rowan Ranger. While these chickens are reported to grow at rates better suited to organic production than previously available strains, anecdotal evidence suggested increased fearfulness in this strain and concerns were raised that this may deter the birds from accessing the range. We subjected Rowan Rangers and fast-growing Ross 308 raised on the same organic farm to a set of behavioural tests while also tracking activity and outdoor use. The results suggest that although Rowan Rangers indeed show longer durations of tonic immobility, an index of predator-related fear, both strains made an outdoor visit on average once every $1.5 \mathrm{~h}$ and typically spent around 5\% of their days in the range. Overall however, our results support the transition to Rowan Rangers in organic chicken production in Sweden.
\end{abstract}

Keywords: animal welfare, organic chicken production, novel object, Ross 308, tonic immobility

\title{
Introduction
}

Organic chicken production is currently experiencing a major growth spurt in Sweden, with an increase of more than $300 \%$ from 2014 to 2016 and currently producing over 700,000 chickens yearly (KRAV, 2017). Due to small-scale production and strict import regulations conventional fast-growing broiler hybrids such as Ross 308 or Cobb 500 have until recently been the only chicken strains available for organic chicken farms in Sweden. These hybrids, intensely selected for high feed efficiency and rapid weight gain, grow too fast for organic production where a maximum growth rate of $45 \mathrm{~g} /$ day is desirable. EU legislation effectively penalises the use of fast-growing animals by requiring the growing period to be at least 10 days longer for these animals (European Economic Community, 2008; KRAV, 2016). 
Eriksson et al. (2010) showed that even with qualitative feed restriction Ross 308 chickens achieved growth rates of 58 g/day in an organic farm setting. In late 2014, the Rowan Ranger strain was first introduced in Sweden as a slower-growing alternative with reported growth rates of 43 g/day with high-quality feed (Damme et al., 2015).

While Rowan Rangers appear better suited for organic and/or free-range production in terms of growth rate, early anecdotal reports suggested that this strain may be more fearful than the conventional hybrids. Increased fearfulness could potentially diminish the birds' use of the outdoor range, which would largely defeat the purpose of raising free-range chickens and could have detrimental effects on animal welfare (Campbell et al., 2016; Stadig et al., 2016). Such effects could arise from not making use of the provided outdoor space and the behavioural opportunities associated with it, as well as from a lower intake of certain vitamins and amino acids available in forage but not in sufficient amounts in organic feedstuffs (Dal Bosco et al., 2010). Concerns about low use of outdoor ranges in free-range chickens have previously been raised for both layer (e.g. Gilani et al., 2014) and broiler chickens (Weeks et al., 1994; Dawkins et al., 2003). If Rowan Rangers would indeed turn out to be a more fearful broiler strain than the ones previously used, it is possible that outdoor ranges would require some form of remodelling to provide these animals with an attractive outdoor environment (cf Dawkins et al., 2003). In general it appears that while only a small percentage of the chicken flock (14-22 \%) can typically be found outdoors at any one time, most free-range chickens in both broiler and layer flocks do use the outdoor run at intervals ranging from several times per day to once every few days (Dawkins et al., 2003; Richards et al., 2011; Gilani et al., 2014).

In this study we quantified the outdoor range use, activity levels, fearfulness and indoor behaviour patterns of 8-week old Rowan Ranger and Ross 308 chickens raised in separate flocks under commercial organic farm conditions in southern Sweden. We hypothesized that 
Rowan Ranger chickens would exhibit higher levels of fearfulness and reduced outdoor range use.

\section{Material and methods}

\section{Animal management}

The current study was carried out on two cohorts of 8-week-old (Ross: 53-56 days, Rowan Ranger: 55-60 days) free-range unsexed broiler chickens at an organic commercial farm in southern Sweden during Sept-Oct 2015. All animals used in the study were raised according to Swedish legislation and the requirements for organic chicken production set by KRAV, the main Swedish certifier for organic food production (KRAV, 2016). In short, the animals were raised in heated indoor houses in flocks of approx. 4,500 birds until 3 weeks of age, and then moved to moveable housing units $\left(250 \mathrm{~m}^{2}\right)$ in flocks of around 1,500 birds. The study included Rowan Rangers from three such houses and Ross 308 from four houses. Due to factors outside of our control, data from the Ross birds could only be collected during a shorter time span (4 vs 6 days) which led to uneven sample sizes for the two strains. Outdoor access was introduced at 4-5 weeks of age, and was manually controlled by the farmer opening the pop holes and main doors in the morning (approx. 06:00) and closing them at night (approx. 21:00). Lighting was manually switched on and off at the same times. Weather conditions were similar throughout the sampling period within strains, however the Rowan Ranger flock hatched slightly earlier in the season and experienced higher temperatures (average $16{ }^{\circ} \mathrm{C}$ ) but with higher wind speeds (average $6.5 \mathrm{~m} / \mathrm{s}$ ) and more precipitation (average $4.0 \mathrm{~mm} /$ day) compared to the Ross birds $\left(10^{\circ} \mathrm{C}, 4.3 \mathrm{~m} / \mathrm{s}, 1.0 \mathrm{~mm}\right.$ daily). It has previously been shown that higher temperatures will encourage range use, while wind and rain will discourage from it (Stadig et al., 2016). At the time of the study, the outdoor ranges were mainly grassland and did not offer much cover (Figure 2), however the entire farm was 
fenced to prevent attacks by mammalian predators. Animals were fed according to Swedish commercial practice for the respective breeds in organic production. During the first 20 days, all animals received the same starter feed (12.4 MJ/kg, $23.8 \%$ crude protein). From 21 days until slaughter age at 71 days, different grower feeds were given to the Ross 308 (11.1 MJ/kg, 14.7 \% crude protein) and Rowan Ranger (12.5 MJ/kg, $20.2 \%$ crude protein) flocks to achieve similar growth and the desired slaughter weight. Feed and water was always available ad libitum and were supplemented with fishmeal during the first 4 weeks. The study was noninvasive and performed on privately owned animals with the informed consent of the owner, which complies with relevant Swedish legislation. A general overview of the timing of sampling procedures is depicted in Figure 1.

\section{Outdoor use and activity tracking}

Activity and light loggers (MotionWatch 8, CamNTech, Cambridge, UK) were attached by thin rubber straps around the wing bases and worn as backpacks for $23 \mathrm{~h}$ each (afternoon to afternoon) by each of the birds monitored. Each logger weighs approximately 9 g, measures $36 \mathrm{~mm} \times 28 \mathrm{~mm} \times 9 \mathrm{~mm}$, and the animals showed no signs of discomfort of wear once their feathers had re-settled, which is in accordance with our previous experience. Data collection included 36 Rowan Ranger from 3 houses and 20 Ross 308 chickens from 4 houses, however data from three Ross birds were lost due to technical malfunctions. Animals were colourmarked on their backs (Porcimark marking spray, Jørgen Kruuse A/S, Denmark) at the time of logger placement to avoid re-sampling on a subsequent day even if the logger was dropped. Time-stamped activity and light data were recorded every second and analysed to determine time spent outdoors and active time. An individual was considered to make an outdoor visit when the logger recorded a light level of at least 300 lux, so these data include animals that were e.g. sitting in the pop holes without fully leaving the house. An individual was considered to be indoors when the logger recorded a light level below 125 lux. Light levels 
between 125-300 lux were considered ambiguous and were not included in the analysis, they constituted approximately $1.1 \%$ of recorded data. An individual was considered to be in an active bout when the logger recorded at least 20 counts/s. This threshold was set to reflect a reasonably high level of activity and to reduce noise from behaviours such as pecking, preening and wing stretching based on the current data set. Both light and activity data were normalized to day length to account for variations due to season and daily fluctuations in opening/closing time of the pop holes.

\section{Fear tests}

At the time of logger removal in the afternoon, the same 36 Rowan Rangers and 20 Ross 308 birds were weighed and subjected to two tests of individual fearfulness. First, tonic immobility (TI) was induced by placing the chicken on its back and manually restraining it for $15 \mathrm{~s}$. Induction was considered successful once the animal remained immobile for at least $10 \mathrm{~s}$ following a maximum of 3 induction attempts. The latency to first head movement and total duration to righting were both recorded. TI was interrupted after $5 \mathrm{~min}$. This is the standardized way of TI testing in poultry, and is a simulated way of eliciting an anti-predator response (Forkman et al., 2007). Second, the animals were subjected to social isolation (SI) by being individually placed in a blacked-out cardboard box for 5 min while vocalizations were recorded. The recordings were analysed for the latency to start vocalizing and the type and number of vocalizations. Vocalization types were identified spectrographically (Adobe Audition 2015, Adobe Systems, San Jose, CA, USA) and categorized as distress calls (including distress squawks), fear trills or other calls based on previously reported descriptions by Collias and Joos (1953), Collias (1987) and Marx et al. (2001).

In addition, group-level novel object (NO) tests were carried out following the procedure outlined in the Welfare Quality assessment for poultry (Welfare Quality, 2009). The test was typically carried out around 09:00. In brief, two experimenters waited at a chosen position in 
the chicken house for 5 min before placing a $50 \mathrm{~cm}$ long stick painted in colourful stripes in the litter and moving $1.5 \mathrm{~m}$ away. The number of chickens within one body length of the stick was then recorded every $10 \mathrm{~s}$ during a total of $2 \mathrm{~min}$. The test was repeated twice in each house at different locations but in immediate succession and the average from each house used for further analysis giving us 4 measurements from Ross houses and 3 measurements from Rowan Ranger houses. While this test is originally described for laying hens, we decided to use it due to the lack of behaviourally based welfare assessments available for broiler chickens.

\section{Focal sampling of indoor behaviours}

In addition to the loggers and fear tests, a classic focal sampling of behaviours was performed. To facilitate observations a subsection of the house was cordoned off by a mesh fence (approx. $3 \mathrm{~m} \times 5 \mathrm{~m}$, fence $0.7 \mathrm{~m}$ high) placed on the day before the sampling was performed. Water nipples and feeders were always available within the subsections, and animals were free to go in and out of the subsection at will. Within this area, two experimenters observed 4 randomly chosen focal animals each during a total of 20 min using a rotating focal sampling schedule with an interval of $20 \mathrm{~s}$ for a total of 60 observations per session. Note that each observation could consist of more than one behaviour. Each house was used for 2-6 separate sampling sessions on different days and each session (18 Rowan Ranger sessions, 8 Ross sessions) treated as a statistical unit. The recorded behaviours and their grouping categories were based on a standard chicken ethogram (Eklund \& Jensen, 2011) and is presented in Table 1.

\section{Statistical analysis}

Comparisons between the means of two groups (body weights, logger data, vocalizations and focal behaviours) were done by unpaired permutation tests in StatBoss Permutations Tester. 
Permutation tests were used because they make fewer assumptions than t-tests and are valid even if the population distribution is non-normal and sampling not strictly normal (Lew, 2008). Note that the permutation test produces no test statistic other than the $P$ value. House and day of sampling were excluded as factors as no significant effects were seen. MiniTab 17 (MiniTab Inc, State College, PA, USA) was used to analyse behavioural latencies (tonic immobility, latency to vocalize) by Kaplan-Meier survival curves with Log-Rank tests, and novel object data by a repeated measures ANOVA. $\mathrm{P}<0.05$ was considered significant. Results are presented as mean \pm standard deviation and error bars also denote standard deviations where present.

\section{Results}

Based on the light data recorded by activity loggers worn on the chickens' backs, $88 \%$ (15/17) of the Ross chickens and $97 \%$ (35/36) of the Rowan Ranger chickens used the outdoor range during their logged day. While the Rowan Rangers made more outdoor visits than the Ross during the morning $(1.11 \pm 1.07$ vs. $0.50 \pm 0.56$ visits/h; $\mathrm{P}=0.026)$ there was no overall difference in the number of outdoor visits ( $0.87 \pm 0.69$ vs. $0.64 \pm 0.55$ visits/h; Figure $3 \mathrm{~A}$ ) and no difference in the total time spent outside when correcting for variations in day-length. Both Rowan Rangers and Ross made an outdoor visit on average once every $1.5 \mathrm{~h}$ and spent approximately $5 \%$ of their day in the outdoor range (Figure $3 \mathrm{~A}-\mathrm{B}$ ). There was also no difference in average duration of the outdoor visits for the two groups ( $3.5 \pm 2.6 \mathrm{~min}$ vs. $4.0 \pm 2.5$ min for Rowan Rangers and Ross respectively). Although more or less equally prone to venture outside there was a clear difference in overall activity level (Figure 3 C-D), with a higher activity level observed in the Ross birds during the daytime both in terms of active bouts per hour ( $47.3 \pm 5.7$ vs. $39.3 \pm 4.3$ bouts/h; $\mathrm{P}<0.0001)$ and in percentage of daytime spent in an active bout $(43.2 \% \pm 8.2 \%$ vs. $30.9 \% \pm 5.9 \% ; \mathrm{P}=0.009)$. There was no difference in bout duration, which averaged around $30 \mathrm{~s}$ for both strains. It is worth noting 
that while both strains were largely inactive during the night, Ross birds engaged in significantly more active bouts also during the night, being active during $5.3 \% \pm 1.9 \%$ of the night (Rowan Rangers: $2.6 \% \pm 1.0 \%$; $>0.0001$ ). Bout duration was shorter during the night, averaging around $15 \mathrm{~s}$.

In the TI test, Rowan Ranger birds showed significantly longer total duration of immobility (P $=0.019$; Figure 4 A). There was no significant difference in the latency to first head movement $(\mathrm{P}=0.7)$ or the number of induction attempts $(\mathrm{P}=0.063)$ needed between the two strains. Induction was successful in $72 \%$ of the Rowan Rangers and $45 \%$ of the Ross 308 . In the SI test, both strains performed similar amounts of distress and fear calls but Rowan Rangers made significantly more 'other calls' $(\mathrm{P}=0.048$; Figure $4 \mathrm{~B})$. There was no difference in the latency to first vocalization between the strains (Figure 4 C), with the majority of birds (81 \% of Ross 308, 75 \% of Rowan Rangers) starting to vocalize within 30 S.

Comparing the behaviour of the two strains indoors, Rowan Rangers performed significantly more resting $(\mathrm{P}<0.0001)$ and comfort behaviours $(\mathrm{P}=0.044)$ while Ross birds spent significantly more time feeding $(\mathrm{P}<0.0001)$ (Figure $5 \mathrm{~A}$ ). Even though Ross animals spent about twice as much time feeding, there was no significant difference in body mass between the strains (2468 $\pm 307 \mathrm{~g}$ for Ross vs. $2290 \pm 333 \mathrm{~g}$ for Rowan Rangers). In the novel object test the Rowan Ranger flock approached the colourfully banded stick in significantly larger numbers than the Ross flock $(\mathrm{P}<0.0005)$, averaging 1.5 birds within a bird-length from it during the 2 min testing time while very few Ross birds (average 0.4) came close (Figure 5 B).

\section{Discussion}


Results from this study suggest that while only a small proportion of free-range broiler flocks may be observed outdoors at any one time, the large majority of birds (88-97\%) did indeed use the outdoor perimeter. This is in line with previous studies on free-range laying hens showing that only 3-14 \% of the animals never accessed the pop holes (Richards et al., 2011; Hartcher et al., 2016; Larsen et al., 2017). While it can certainly still be argued that improved cover from aerial predators and/or harsh weather conditions may increase the animals' use of the outdoor range or at least improve their perception of it (Dawkins et al., 2003; Dal Bosco et al., 2014; Gilani et al., 2014), we find no support for the common notion that only a few of the animals make use of their outdoor access (Weeks et al. 1994; Dawkins et al., 2003).

One of the main reasons for conducting this study was a concern of higher fearfulness in the newly introduced Rowan Rangers compared to the already well-known Ross 308, and the TI results do indeed show higher predator fear in the slow-growing strain. This fearfulness did however not affect the animals' tendency to go outdoors. It may have had an effect on the ranging distance from the house, as Ross 308 were generally seen dispersed over a larger area than the Rowan Rangers which tended to keep close to the house (Figure 2) but this could not be quantified using our monitoring method. Using camera recordings of outdoor use, Stadig et al. (2016) showed that broiler flocks with lower TI durations were more likely to range more than $5 \mathrm{~m}$ from the house, and correlations between TI durations and outdoor use have been reported on the individual level in laying hens (Larsen et al., 2017). Based on this and other reports it is likely that improved cover in the outdoor range would encourage the Rowan Rangers to use a larger part of the run (Dawkins et al., 2003; Stadig et al, 2016) which would also reduce the risk of point pollution and local depletion of forage. While increased use of the outdoor area may be desirable from both animal welfare and consumer perception perspectives, it is also worth noting that some level of predator fear should probably be considered adaptive for free-range chickens. The current farm was successfully fenced against 
mammalian predators, but occasional attacks by crows (Corvus cornix) and buzzards (Buteo buteo) were reported and red kites (Milvus milvus) were often sighted above the farm. While avian predators rarely kill more than one bird at a time they can be responsible for a high number of attacks on free-range chickens (Stahl et al., 2002), especially in ranges with a low amount of cover (Dal Bosco et al., 2014), and so increased coverage of the range can be expected to increase animal welfare both in terms of reduced fear and increased outdoor use and decreased mortality due to raptor attacks. Increased range coverage could also offer protection against harsh weather and may increase outdoor use also during unfavourable weather conditions such as harsh wind, rain or strong sunlight (Stadig et al., 2016). In the current study, the two strains did experience slightly different weather conditions. While we cannot entirely exclude this as a confounding factor in our results, no extreme weather was recorded during the sampling periods and effects are expected to have been small (cf Hegelund et al., 2005; Stadig et al., 2016).

The SI test showed no clear pattern of differences in fearfulness between the strains, indicating that the difference in fearfulness may be specific to predator-related fear. As expected in social isolation, both strains mostly performed distress calls (Marx et al., 2001). Further support that the Rowan Rangers may not be generally more fearful, just more wary of predators, comes from the NO test where this strain was instead showing less fear than the Ross 308. The reason for this is not clear, but it is worth noting that the NO test employed in this study was initially designed as a welfare test for laying hens (Welfare Quality, 2009). While the test has not been validated as a welfare test in broiler chickens, this may be an indication that Rowan Ranger chickens experience better welfare under organic conditions than do Ross 308.

In addition to the outdoor-use tracking and fear tests, the focal sampling of indoor behaviours gives us an overall idea of daily life as experienced by the two strains. The higher incidence 
of resting and comfort behaviours in Rowan Rangers may suggest a better welfare in these animals compared to the Ross 308 (Zimmerman et al., 2011). While high levels of resting behaviours can also be the result of leg injuries and pain, no signs of poor leg health were observed in the Rowan Rangers and only a few Ross birds showed signs of impaired walking ability. Results from the focal sampling also give us a clue as to why a difference in welfare may be present, with Ross birds spending on average twice as much time on feeding behaviours compared to the Rowan Rangers. While this is partly a behaviour that the fastgrowing Ross strain has been actively selected for, it is quite likely that the excessive foraging is also a result of the qualitative feed restriction that these birds are raised on to maintain a sufficiently low growth rate for organic production. In previous studies comparing organically reared Ross birds to slow-growing strains under ad libitum feeding conditions, Ross birds typically show low levels of locomotive behaviour and low interest in using the outdoor range (Weeks et al., 1994; Castellini et al., 2016) and we expect that the discrepancy between these studies and the results reported here are due to the qualitative feed restriction imposed on the Ross birds in our study. It is well established that growth restriction by restricted feeding leads to correlated increases in both feeding motivation and activity level (Savory \& Lariviere, 2000), and hunger frustration is probably also the reason for the higher activity levels recorded in Ross birds at all times of the day and even during night-time. While it could be reasoned that a pre-occupation with feeding may be the reason for the low interest of Ross birds in the NO in this study, our experience with this fear test suggests that hunger usually has the opposite effect on NO interest (unpublished data). Note however that some form of feed-restriction is in practice the only way of raising a fast-growing broiler strain commercially under organic conditions as legislation dictates that the animals must reach a certain age before slaughter, while slaughterhouses and consumer expectations demand birds of a certain size. 


\section{Conclusions}

The Rowan Ranger strain exhibits behavioural signs of a potentially better welfare situation under organic rearing conditions compared to the Ross 308. Such a difference in welfare can be expected to be largely linked to feeding behaviours and growth capacities which differ wildly between the two strains. While our study could confirm increased levels of predatorrelated fear in the more slow-growing strain, we saw no effect of this fear on propensity to venture outdoors or on the total amount of time spent outdoors which suggests that this fearfulness will not reduce the welfare of Rowan Rangers in free-range farming.

\section{Acknowledgements}

The authors would like to thank Johanna and Mårten Rasmusson for allowing access to their farm and animals. The study was funded by grant 2013-293 from Swedish research council Formas, a career grant from Linköping University to JA, and the Swedish Centre of Excellence in Animal Welfare Science. 


\section{References}

Campbell, D. L. M., Hinch, G. N., Downing, J. A. and Lee, C. (2016). Fear and coping styles of outdoor-preferring, moderate-outdoor and indoor-preferring free-range laying hens. Applied Animal Behaviour Science 185, 73-77. doi:10.1016/j.applanim.2016.09.004

Castellini, C., Mugnai, C., Moscati, L., Mattioli, S., Guarino Amato, M., Cartoni Mancinelli, A. \& Dal Bosco, A. (2016). Adaptation to organic rearing system of eight different chicken genotypes: behavior, welfare and performance. Italian Journal of Animal Science 15(1), 3746. doi:10.1080/1828051X.2015.1131893

Collias, N. \& Joos, M. (1953). The spectrographic analysis of sound signals of the domestic fowl. Behaviour, 5, 175-188. doi:10.1163/156853953x00104

Collias, N. (1987). The vocal repertoire of the red junglefowl: a spectrographic classification and the code of communication. The Condor 89, 510-524. doi:10.2307/1368641

Dal Bosco, A., Mugnai, I., Sirri, F., Zamparini, C. \& Castellini, C. (2010). Assessment of a global positioning system to evaluate activities of organic chickens at pasture. Journal of Applied Poultry Research 19, 213-218. doi:10.3382/japr.2010-00153

Dal Bosco, A., Mugnai, C., Rosati, A., Paoletti, A., Caporali, S. \& Castellini, C. (2014). Effect of range enrichment on performance, behavior and forage intake of free-range chickens. Journal of Applied Poultry Research 23, 137-145. doi:10.3382/japr.2013-00814

Damme K., Keppler, C., Hausleitner, M., Bachmeier, J., Hartmann, J., Louton, H. \& Rauch, E. (2015). Untersuchungen unterschiedlicher langsam wachsender Premiumhähnchen unter Tierschutz-Label-Konditionen. Teil I: Mast- und Schlachtleistungskriterien [Test of different premium broiler genotypes under Animal Welfare Label conditions. Part I: Fattening and 
slaughter yield]. European Poultry Science, 79. doi:10.1399/eps.2015.85 (In German with English summary.)

Dawkins, M. S., Cook, P. A., Whittingham, M. J., Mansell, K. A. \& Harper, A. E. (2003). What makes free-range broiler chickens range? In situ measurement of habitat preference. Animal Behaviour, 66, 151-160. doi:10.1006/anbe.2003.2172

Eklund, B. \& Jensen, P. (2011). Domestication effects on behavioural synchronization and individual distances in chickens (Gallus gallus). Behavioural Processes, 86, 250-256. doi:10.1016/j.beproc.2010.12.010

Eriksson, M., Waldenstedt, L., Elwinger, K., Engström, B. \& Fossum, O. (2010). Behaviour, production and health of organically reared fast-growing broilers fed low crude protein diets including different amino acid contents at start. Acta Agriculturae Scandinavica. Section AAnimal Science, 60, 112-124. doi:10.1080/09064702.2010.502243

European Economic Community. (2007). Commission Regulation (EC) No 889/2008 of 5 September 2008 laying down rules for the implementation of Council Regulation (EC) No 834/2007 on organic production and labelling of organic products with regard to organic production, labelling and control. European Economic Community, Brussels, Belgium.

Forkman, B., Boissy, A., Meunier-Salaün, M.-C., Canali, E., \& Jones, R. B. (2007). A critical review of fear tests used on cattle, pigs, sheep, poultry and horses. Physiology \& Behavior 92, 340-374. doi:10.1016/j.physbeh.2007.03.016

Gilani, A.-M., Knowles, T. G. \& Nicol, C. J. (2014). Factors affecting ranging behavior in young and adult laying hens. British Poultry Science, 55(2), 127-135. doi:10.1080/00071668.2014.889279 
Hartcher, K. M., Hickey, K. A., Hemsworth, P. H., Cronin, G. M., Wilkinson, S. J. and Singh, M. (2016). Relationships between range access as monitored by radio frequency identification technology, fearfulness, and plumage damage in free-range laying hens. Animal 10(5), 847853. doi:10.1017/S1751731115002463

Hegelund, L., Sørensen, J. T., Kjær, J. B. and Kristensen I. S. (2005). Use of the range area in organic egg production systems: effect of climatic factors, flock size, age and artificial cover. British Poultry Science 46(1):1-8. doi:10.1080/00071660400023813

KRAV (2016). Regler för KRAV-certifierad produktion [Standards for KRAV-certified production], chapter 5.5. Växjö: Grafiska Punkten. (In Swedish).

KRAV (2017). Marknadsrapport 2017: Lamm, grisar, höns och kyckling [Market report 2017: Lambs, pigs, hens and chickens]. http://www.krav.se/marknadsrapport2017/lantbruk/lamm_grisar_hons_kyckling. Accessed 2017-04-26. (In Swedish).

Larsen, H., Cronin, G. M., Gebhardt-Henrich, S. G., Smith, C. L., Hemsworth, P.H. and Rault, J.-L. (2017). Individual ranging behaviour patterns in commercial free-range layers as observed through RFID tracking. Animals 7(21). doi:10.3390/ani7030021

Lew, M. J. (2008). On contemporaneous controls, unlikely outcomes, boxes and replacing the 'Student': Good statistical practice in pharmacology, problem 3. British Journal of Pharmacology, 155, 797-803.

Marx, G., Leppelt, J. \& Ellendorff, F. (2001). Vocalisation in chicks (Gallus gallus dom.) during stepwise social isolation. Applied Animal Behaviour Science, 75, 61-74. doi:10.1016/s0168-1591(01)00180-0

Richards, G. J., Wilkins, L. J., Knowles, T. G., Booth, F., Toscano, M. J., Nicol, C. J. \& Brown, S. N. (2011). Continuous monitoring of pop hole usage by commercially housed free- 
range hens throughout the production cycle. Veterinary Record, 169, 338. doi:10.1136/vr.d4603

Savory, C. J. \& Lariviere, J.-M. (2000). Effects of qualitative and quantitative food restriction treatments on feeding motivational state and general activity of growing broiler breeders. Applied Animal Behaviour Science 69, 135-147. doi:10.1016/S0168-1591(00)00123-4

Stadig, L. M., Rodenburg, T. B., Ampe, B., Reubens, B. and Tuyttens, F. A. M. (2016). Effect of free-range access, shelter type and weather conditions on free-range use and welfare of slow-growing broiler chickens. Applied Animal Behaviour Science (in press). doi:10.1016/j.applanim.2016.11.008

Stahl, P., Ruette, S. \& Gros, L. (2002). Predation on free-ranging poultry by mammalian and avian predators: field loss estimates in a French rural area. Mammal Review, 32(3), 227-234. doi:10.1046/j.1365-2907.2002.00110.x

Weeks, C. A., Nicol, C. J., Sherwin, C. M. \& Kestin, S. C. (1994). Comparison of the behavior of broiler chickens in indoor and free-range environments. Animal Welfare, 3, 179192.

Welfare Quality (2009). Welfare Quality assessment protocol for poultry (broilers, laying hens). Welfare Quality Consortium, Lelystad, Netherlands.

Zimmerman, P. H., Buijs, S. A. F., Bolhuis, J. E. and Keeling, L. J. (2011). Behaviour of domestic fowl in anticipation of positive and negative stimuli. Animal Behaviour 81, 569-577. doi:10.1016/j.anbehav.2010.11.028 


\section{Tables with captions}

Table 1. Behaviours recorded during the focal sampling with descriptions and categories.

\section{Category Functional term Description}

\begin{tabular}{|c|c|c|}
\hline \multirow[t]{4}{*}{ Feeding } & Eating & Head in feeder and/or pecking at supplied feed. \\
\hline & Drinking & Pecking at water nipple or in cup beneath nipple. \\
\hline & Ground pecking & Pecking movements directed at ground. \\
\hline & Scratching & Scratching the litter with feet. \\
\hline Dust-bathing & Dust-bathing & $\begin{array}{l}\text { Lying with puffed feathers, rubbing head or body in } \\
\text { litter, vertical wing shaking. }\end{array}$ \\
\hline \multirow[t]{3}{*}{ Comfort } & Preening & Grooming own feathers using beak. \\
\hline & Stretching & Extending wing and/or leg backwards. \\
\hline & Wing-flapping & Flapping of wings with upright posture. \\
\hline Resting & Lying down & $\begin{array}{l}\text { Body resting in litter, no head movements, eyes open } \\
\text { or closed. }\end{array}$ \\
\hline \multirow[t]{2}{*}{ Locomotion } & Standing up & Standing still without moving, alert posture. \\
\hline & Walking & Moving forward at any pace. \\
\hline Aggression & Aggression & $\begin{array}{l}\text { Bird walks after conspecific with head held high, other } \\
\text { bird retreating. Bird stands in front of conspecific and } \\
\text { flaps its wings more than once at distance }<0.5 \mathrm{~m} \text {. } \\
\text { Aggressively pecking other bird. }\end{array}$ \\
\hline Other & Other & All behaviours not mentioned above. \\
\hline
\end{tabular}




\section{Figure captions}

Figure 1. Outline of a day during the sampling period. Loggers were set to start at 15:00 after an initial habituation period and removed around noon the following day. Samplings were staggered so that NO tests and focal sampling took place in houses separate from where birds were being logged to minimize experimenter interference.

Figure 2. Photo of Rowan Rangers in the outdoor range, showing the minimal amount of cover available at the time of the study and the typically observed dispersal around the chicken house for this strain.

Figure 3. (A,B) Rowan Rangers made significantly more outdoor visits per hour during the morning, but overall there was no difference in either the number of outdoor visits or the proportion of time spent outdoors. (C,D) Ross 308 chickens were significantly more active at nearly all times of the day and during the night both in terms of active bouts per hour (C) and the proportion of active time (D).

Figure 4. Rowan Rangers exhibited higher predator-related fear as determined by (A) longer durations of tonic immobility. In the five-minute social isolation test there was (B) no difference in the number of fear-related calls or (C) latency to vocalize.

Figure 5. (A) While indoors, Rowan Rangers performed significantly more comfort and resting behaviours than the Ross 308 birds, who instead displayed significantly more feeding behaviours. (B) The Rowan Ranger flock were also significantly more interested in the novel object. 


\section{Figure 1}

Photo of Rowan Rangers in the outdoor range, showing the minimal amount of cover available at the time of the study and the typically observed dispersal around the chicken house for this breed.






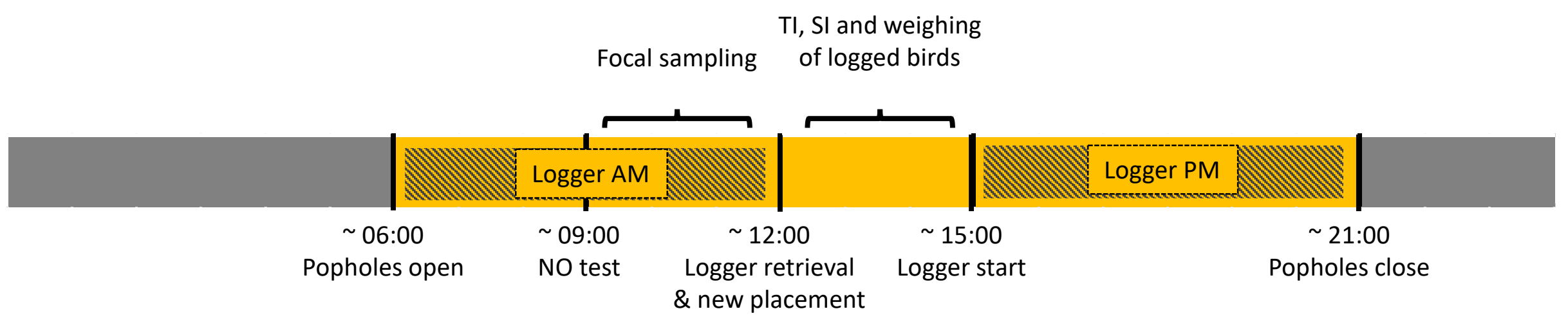

Figure 2. Outline of a day during the sampling period. Loggers were set to start at 15:00 after an initial habituation period. Loggers were then removed at noon the following day and the logged birds subjected to $\mathrm{TI}$ and SI tests and weighing. Samplings were staggered so that NO tests and focal sampling took place in houses separate from where birds were being logged to minimize experimenter interference. 


\section{Figure 3}

$(A, B)$ Rowan Rangers made significantly more outdoor visits per hour during the morning $(P=0.026)$, but overall there was no difference in either the number of outdoor visits or the proportion of time spent outdoors.

(C,D) Ross 308 chickens were significantly more active at nearly all times of the day and during the night both in terms of active bouts per hour (C) and the proportion of active time (D). $P<0.0001$ for all significant comparisons except \% active time during the whole day where $\mathrm{P}=0.009$.
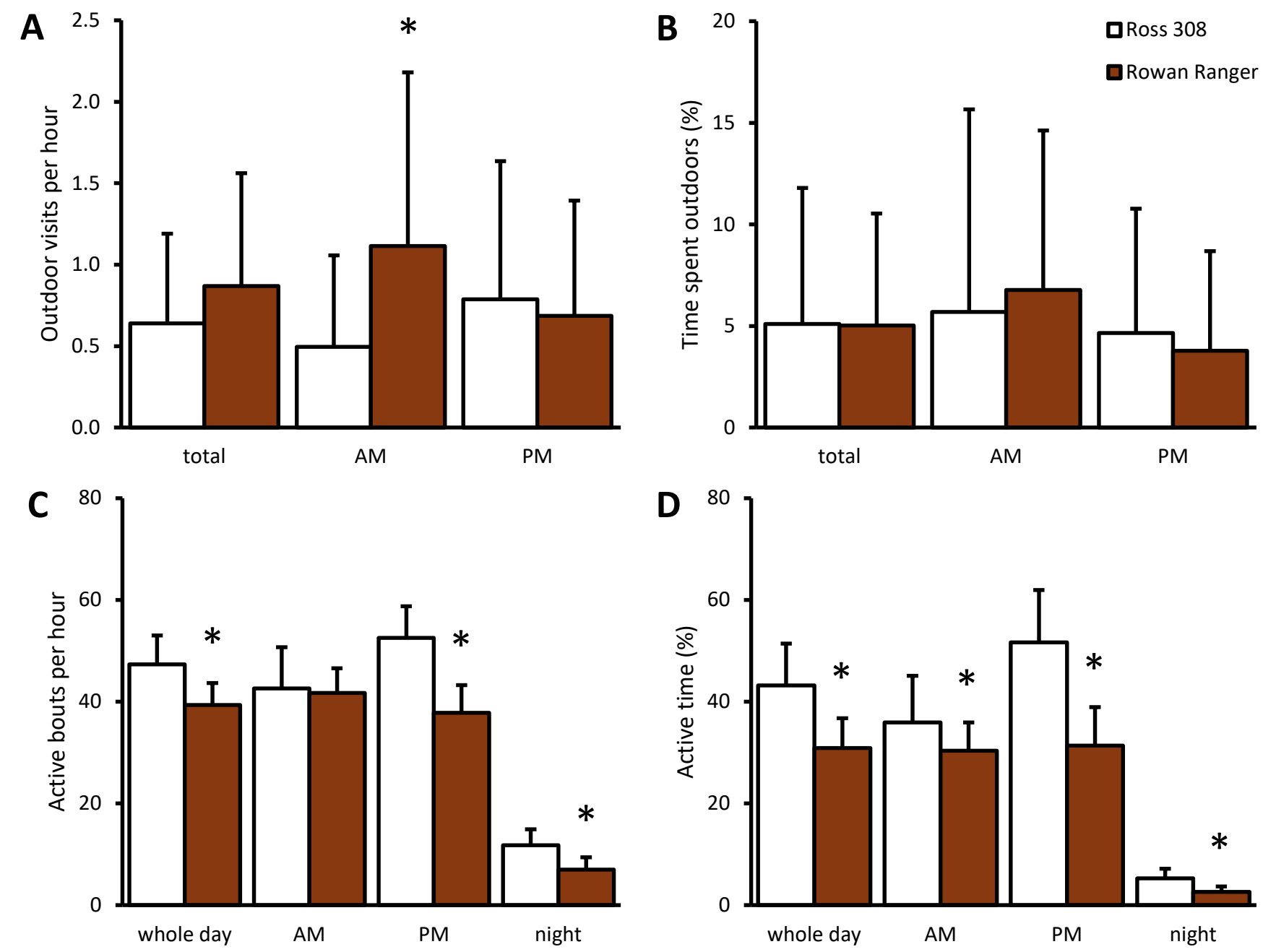
Figure 4
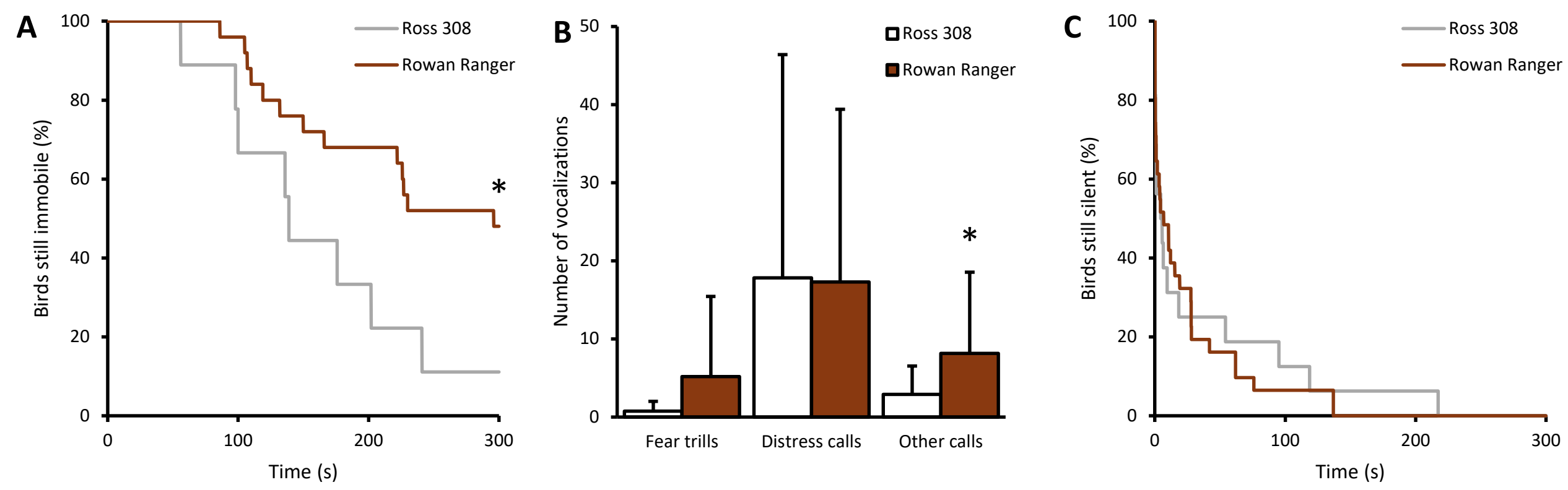


\section{Figure 5}

(A) While indoors, Rowan Rangers performed significantly more comfort $(P=0.044)$ and resting $(P<0.0001)$ than the Ross 308 birds, who instead displayed significantly more feeding behaviour $(P<0.0001)$.

(B) The Rowan Ranger flock were also significantly more interested in the novel object $(F=20.13, P<0.0005)$.
